\title{
Pelletization of composted swine manure solid fraction with different organic co-formulates: effect of pellet physical properties on rotating spreader distribution patterns
}

\author{
Elio Romano • Massimo Brambilla • \\ Carlo Bisaglia • Niccolò Pampuro • \\ Ester Foppa Pedretti · Eugenio Cavallo
}

Received: 8 November 2013/ Accepted: 22 July 2014/Published online: 6 September 2014

(C) The Author(s) 2014. This article is published with open access at Springerlink.com

\begin{abstract}
Introduction In Europe, because of the high production levels of livestock farming in general and pig farming in particular, animal waste management has become increasingly important to comply with the required lowering of livestock farming environmental pressure. Usually manures undergo solid/liquid separation, which generates one clarified liquid fraction and one nutrient-rich solid fraction suitable for in farm composting (both raw and in mixture with other bulking agents). This can be used to produce soil amendments, whose management can be further improved by pelletization that, against
\end{abstract}

E. Romano $\cdot$ M. Brambilla $(\bowtie) \cdot$ C. Bisaglia

Consiglio per la Ricerca e la Sperimentazione in Agricoltura,

Unità di Ricerca per l'Ingegneria Agraria (CRA-ING),

Laboratorio di Treviglio, Via Milano, 43, 24047 Treviglio (BG),

Italy

e-mail: massimo.brambilla@entecra.it

E. Romano

e-mail: elio.romano@entecra.it

C. Bisaglia

e-mail: carlo.bisaglia@entecra.it

N. Pampuro - E. Cavallo

Institute for Agricultural and Earthmoving Machines

(IMAMOTER), National Research Council of Italy (CNR),

Strada delle Cacce, 73, 10135 Torino (TO), Italy

e-mail: n.pampuro@ima.to.cnr.it

E. Cavallo

e-mail: e.cavallo@imamoter.cnr.it

\section{E. F. Pedretti}

Dipartimento di Scienze Agrarie, Alimentari ed Ambientali,

Università Politecnica delle Marche, Via Brecce Bianche 10,

60131 Ancona (AN), Italy

e-mail: e.foppa@univpm.it technological and environmental advantages, has the disadvantage of requiring a quite high energy input.

Results Four different pelleted organic fertilizer formulations made of swine manure solid fraction (SMSF) composted both by itself and with sawdust (SMSF-SD), wood chips (SMSF-WC) and wheat straw were tested to highlight differences in physico-chemical and land distribution features. They were compared with two pelleted organic fertilizers ordinarily available at retailers. Results show that, as far as physical and chemical features are concerned, the greatest difference from the reference products used in this study is found in pellet size distribution after spreading since the disintegrating action of the rotating vanes does not affect the tested formulation with the same intensity as the commercial products. Distribution tests showed that SMSF-SD was the formulation with better longitudinal and transverse distribution, while SMSF was the one showing good transverse but poor longitudinal distribution.

Conclusions In farm pelletizing of SMSF composted with different organic waste materials as co-formulates can turn into organic fertilizer formulations comparable with pelleted organic fertilizers ordinarily available at retailers. SMSF-WC was the formulation with the best resistance to fragmentation induced by spreader vanes. SMSF-SD was the formulation showing better longitudinal and transverse distribution, while SMSF showed good transverse but poor longitudinal distribution. These promising results enhance the importance of co-composting as a way to increase livestock farming sustainability and produce better manure compost for wider agricultural uses.

Keywords Manure management - Sustainability · Biomass densification - Nutrient transport 


$\begin{array}{ll}\text { Abbreviations } \\ \text { ANOVA } & \text { Analysis of variance } \\ \text { C/N } & \text { Carbon:nitrogen ratio } \\ \text { CEN } & \text { European Committee for Standardization } \\ \text { CR } & \text { Collection rate } \\ \text { LSD } & \text { Least significant difference } \\ \text { OM } & \text { Organic matter } \\ \text { SGN } & \text { Size guide number } \\ \text { SMSF } & \text { Swine manure solid fraction } \\ \text { SMSF-SD } & \begin{array}{l}\text { Swine manure solid fraction composted with } \\ \text { sawdust }\end{array} \\ \text { SMSF-WC } & \begin{array}{l}\text { Swine manure solid fraction composted with } \\ \text { wood chips }\end{array} \\ \text { SMSF-WS } & \text { Swine manure solid fraction composted with } \\ & \text { wheat straw } \\ \text { TKN } & \text { Total Kjeldahl nitrogen } \\ \text { UI } & \text { Uniformity index }\end{array}$

\section{Introduction}

Because of the high production levels of livestock farming in general and pig farming in particular (Marquer 2010; Lesschen et al. 2011; FAO 2012), animal waste management (i.e. storage and land application) has become increasingly important at a time of crisis for European agriculture (Vereijken and Hermans 2010; Dries et al. 2012).

With reference to Italy, according to FAO statistics, from 2006 to 2010 a total of $25,096,140$ heads were reared, $36.8 \%$ of which were pigs and $25.8 \%$ were cattle and buffalos (FAO 2012). Within this context, livestock farming distribution turned out to be uneven (Martins 2009): more specifically, the 6th Italian National census of agriculture pointed out that Piedmont, Lombardy and Emilia Romagna are the regions where $63.8 \%$ of the cattle, $69.7 \%$ of dairy cows and $89.7 \%$ of pigs are bred (ISTAT 2012). Such concentration of livestock farming activity makes therefore, critical (both from the environmental and the economical points of view) setting up techniques and technologies for proper management of both manures and elements of plant nutrition (Petersen et al. 2007) in compliance with the required lowering of livestock farming environmental pressure (EU 1991, 2000).

The solid/liquid separation of manures usually generates one clarified fraction with good levels of $\mathrm{NH}_{4}{ }^{+}$-nitrogen and one nutrient-rich organic solid fraction for multiple uses (Zhang and Westerman 1997; Møller et al. 2000, 2002; Petersen et al. 2007; Jørgensen and Jensen 2009; Hjorth et al. 2010) with subsequent optimization of crop nutrient management (Meade et al. 2011). Composting process can further enhance solid fraction recycling (Moral et al. 2009; Brito et al. 2012): it can be performed with or without the addition of co-substrates and/or bulking agents (Georgakakis et al. 1996; Roca-Pérez et al. 2007; Bernal et al. 2009; Huang et al. 2006; Nolan et al. 2011; Li et al. 2012; Bustamante et al. 2012). In this way the final product is: (1) stable and easily transportable (Petersen et al. 2007); (2) in compliance with EU regulations for processed manure products (Mc Carthy et al. 2011; Rao et al. 2007); (3) important for mitigation of nitrous oxide $\left(\mathrm{N}_{2} \mathrm{O}\right)$ emissions from compost amended fields (Meijide et al. 2007; Tomich et al. 2011). As a matter of fact, the slow release of nutrients connected to these amendments was found to significantly minimize the risk of gas emissions into atmosphere (Ball et al. 2004), provided that appropriate timing of $\mathrm{N}$ application is set up to avoid wet conditions, which could lead to high $\mathrm{N}_{2} \mathrm{O}$ fluxes by denitrification (Hayakawa et al. 2009). Moreover, increasing the use of organic amendments would help to reduce the application rate of $\mathrm{N}$ fertilizers that is recognized as the most effective measure of reducing $\mathrm{N}_{2} \mathrm{O}$ emissions (Rees et al. 2013).

The possible compaction into pellets of these composted solids further homogenizes and dehydrates their organic matter (Alemi et al. 2010) enhancing, on the one hand, its uniformity and fertilizing/amending properties and, on the other, increasing the distance that can be run in case of transport of such material from nitrate vulnerable zones to others that are not vulnerable (Mc Mullen et al. 2005; Zebarth et al. 2005; Lopez-Ridaura et al. 2009; Zafari and Kianmehr 2013).

Pellet manufacturing is an energy intensive process. Inside the pelleting machine, the pressure between the roller and the dye, forcing the raw material through the perforations, causes frictional heating (Battacharya et al. 1989). Tumuluru et al. (2011), reviewed that power consumption of commercial pellet mills falls within the range of $48.9-130.7 \mathrm{~kJ} \mathrm{t}^{-1}$ the $37-40 \%$ of which is required to compress the material while the remaining energy is required to overcome friction during compression (Tumuluru et al. 2011). With reference to pellet specific energy consumption, Tabil and Sokhansanj (1996) assessed ranges of $19-90 \mathrm{~kJ} \mathrm{~kg}^{-1}$ partly confirmed by Tumuluru et al. (2011), who reviewed specific energy consumption ranging 59-268.2 $\mathrm{kJ} \mathrm{t}^{-1}$ for pellet mills. At a given densification system, moisture content and other biomass properties (e.g. particle size distribution, biochemical composition) can significantly affect the specific energy requirements of the process (Nielsen et al. 2009; Tumuluru et al. 2011; Gadernejad et al. 2012): anyway, the high energy input required makes it uneconomical and not practical for farmers to directly purchase and operate a pellet mill. Commonly, pellet distribution is carried out with rotating spreaders, designed for granular formulations, whose 
performance and hence evenness of spread pattern depends both on machine engineering (Hofstee 1994, 1995; Kweon and Grift 2006; Parish 2006) and on fertilizer physical properties (Hofstee and Huisman 1990; Aphale et al. 2003; Grift et al. 2006; Suppadit and Panomsri 2010), which are also important to calculate the volume needed to store, transport, handle and calibrate fertilizer spreaders (Agnew and Leonard 2003; Campbell et al. 2010).

In this work, we highlight and compare the physical characteristics of four pelleted organic amendments made of swine manure solid fraction (SMSF) composted by itself and with three different co-formulates to point out how pellet composition, because of its influence on pellet resistance to fragmentation, can affect spreading patterns when distribution takes place by means of rotating spreader.

\section{Methods}

Four different organic mixtures were realized by composting SMSF by itself and with the addition of different amounts of organic materials as co-formulates: in particular, on wet basis, composting formulations contained $18 \%$ sawdust (SMSF-SD), $30 \%$ wood chips (SMSF-WC) and $14 \%$ wheat straw (SMSF-WS). More in detail, composting took place setting up on a concrete floor four windrows as follows:

- SMSF: the windrow consisted in $6,000 \mathrm{~kg}$ of swine solid fraction from screw press separator.

- SMSF-SD: the windrow consisted of $5,000 \mathrm{~kg}$ of swine solid fraction obtained from decanting centrifuge mixed with $900 \mathrm{~kg}$ of sawdust.
- SMSF-WC: it was made of $8,000 \mathrm{~kg}$ of swine solid fraction from screw press separator mixed with $2,400 \mathrm{~kg}$ of woodchips.

- SMSF-WS: made of 5,000 kg of swine solid fraction from screw press separator mixed with $720 \mathrm{~kg}$ of wheat straw.

At windrow constitution, biomasses were thoroughly mixed by means of one cement mixer (rotating drum internally equipped with rotary screw): to optimize composting process, materials were blended in such a way to obtain a theoretical $\mathrm{C} / \mathrm{N}$ ratio of 30 (Bishop and Godfrey 1983), avoiding as much as possible composting performance slow down (due to excess of degradable substrate) as well as nitrogen loss by ammonia volatilization in case of $\mathrm{C} / \mathrm{N}$ ratio lower than 20 (Bernal et al. 2009). After the set-up, windrows were covered with plastic sheets and the process was monitored for 130 days. During this time span temperature inside the windrows as well as environmental temperature had been continuously recorded (Fig. 1) thanks to a multichannel acquisition system (mod. SQ 1600 , Grant Instruments, UK): inside the windrows temperature probes were placed at $0.4 \mathrm{~m}\left(T_{1}\right), 0.8 \mathrm{~m}\left(T_{2}\right)$ and $1.2 \mathrm{~m}\left(T_{3}\right)$ high above the floor. According to Caceres et al. (2006) windrow turning was carried each time two out of three probes recorded an inner temperature exceeding $60{ }^{\circ} \mathrm{C}$. As far as compost moisture is concerned, it was weekly checked, tacking six replicates from the whole volume of each windrow and adding the necessary amount of water to keep it in the range of $60-75 \%$ of dry matter (Bernal et al. 1998). Pelletisation was carried out using the mechanical pelletizer CLM200E (La Meccanica Srl, Padua, Italy) powered by a $0.37 \mathrm{~kW}$ electric motor. The obtained pellets (Fig. 2) were compared with two reference commercial products ("mixed manure" and "chicken
Fig. 1 Temperature trends $\left({ }^{\circ} \mathrm{C}\right)$ recorded during the composting process (daily averages)
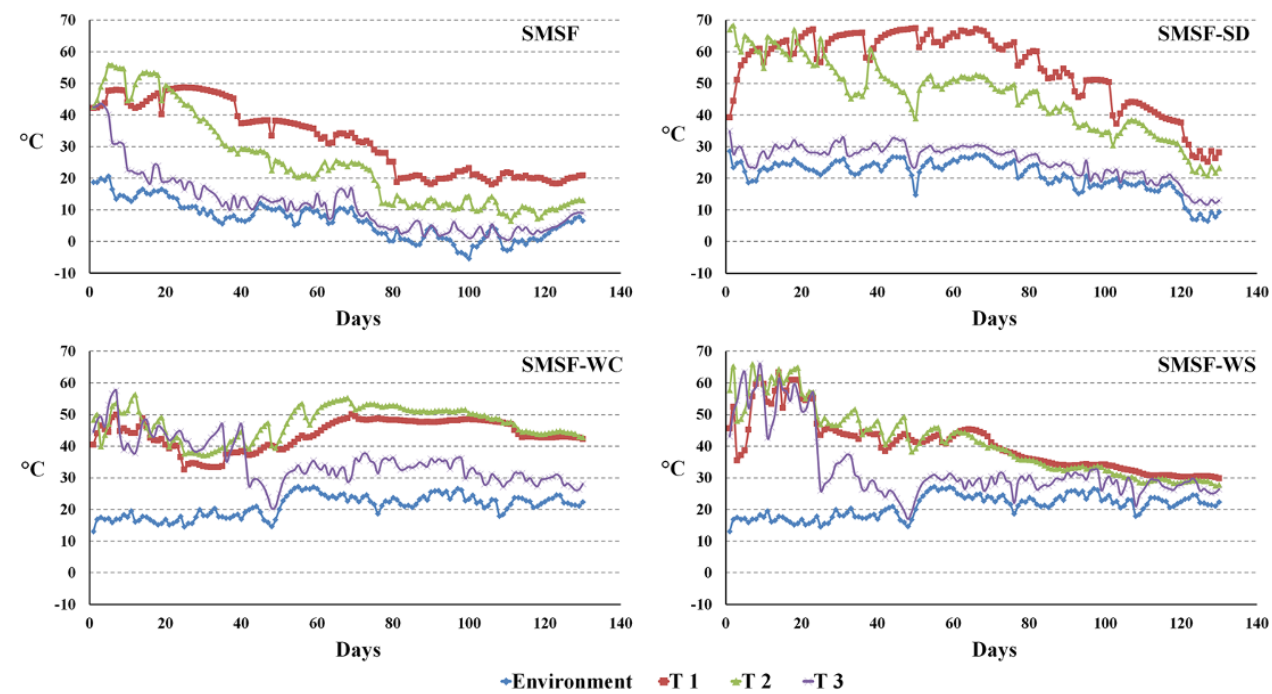


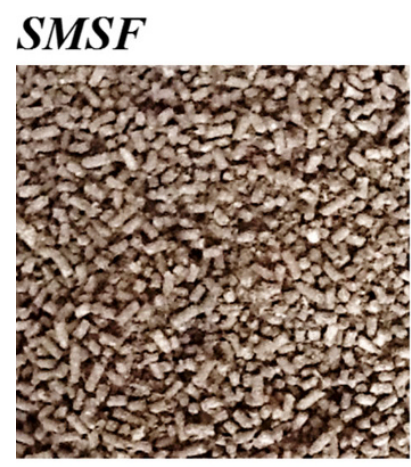

SMSF-WC

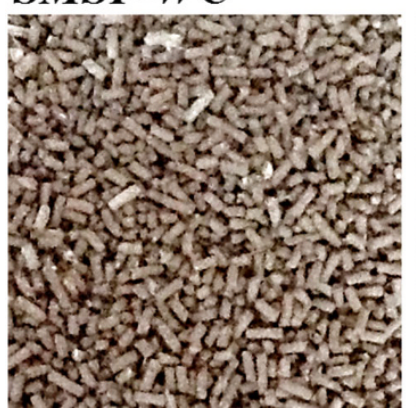

Fig. 2 Pictures of the different types of biomass on purpose pelletized and used in the trial

manure") measuring the following chemical and physical features:

- Organic matter (OM) content according to the incineration method (ASTM D3174-11).

- Total Kjeldahl nitrogen (TKN), according to the regulation of European Union (EU 2003).

- Carbon:nitrogen ratio $(\mathrm{C} / \mathrm{N})$ : as calculus between organic carbon related to TKN.

- Moisture content (\% raw material): samples were put in ventilated oven at $105{ }^{\circ} \mathrm{C}$ until a constant weight was achieved. The moisture content was subsequently expressed as per cent of the raw material (MiPAAF 2012).

- Bulk density $\left(\mathrm{kg} \mathrm{m}^{-3}\right)$ : it was measured using $1 \mathrm{~L}$ plastic cylinder slowly hand filled to reduce compaction (Paré et al. 2009)

- Average length and diameter (mm): 31 single pellets were randomly chosen for each formulation and their length and diameter were measured using a precision vernier caliper.

- Particle size distribution: $300 \mathrm{~g}$ of each sample was placed on top of a set of sieves $(20 \mathrm{~cm}$ diameter, equipped with a collecting container at the bottom and a lid at the top) with the meshes of 20, 10, 7, 5, 2 and $0.5 \mathrm{~mm}$ placed in descending order from top to bottom. The entire series of sieves has been subjected to shaking for $5 \mathrm{~min}$ with a frequency of $0.5 \mathrm{~Hz}$. At the end of the procedure the various fractions remaining on the sieves and in the lower container were collected and weighed. This datum was used to determine size guide number (SGN, mm) and uniformity index (UI, \%) of the pellets: the SGN is the average particle diameter of the product expressed in $\mathrm{mm}$ and multiplied by 100; the UI is the ratio between large and small particles multiplied by 100 (Allaire and Parent 2003, 2004).

After spreading, the collected material underwent sieving as well to compare differences of weight percentages before/after spreading of three cumulative size fractions (">5 mm", "from 5 to $2 \mathrm{~mm}$ " and " $<2 \mathrm{~mm}$ ") to assess the effect of the spreader.

Spreading trials were carried out using one double flat disc rotating spreader (Lely Industries, mod. C 1000, NL). During trials tractor's power take off was set at $480 \mathrm{rpm}$ causing spreading discs to rotate at $1,582 \pm 151 \mathrm{rpm}$. The spreading height was set at $1 \mathrm{~m}$ from the ground.

One experimental area of $900 \mathrm{~m}^{2}$ was set up: it was equipped with 69 plastic containers $(500 \times 500 \times$ $100 \mathrm{~mm}$ ) to collect the pellet thrown by the spreader on a perfectly flat and paved area (Fig. 3). Container's distribution arrangement is shown in Fig. 4: three collecting repetitions (7 containers each) were set up both in "columns" parallel to the direction of travel of the tractor (at two different distances) and in "rows" (9 containers each) transverse to the direction of travel of the vehicle. Containers were all spaced $0.5 \mathrm{~m}$ apart with exception for those at the intersections between longitudinal and transverse replications where they were adjacent.

After spreading the amount of material retained by each container was sieved and weighed to: (1) compare after the spreading the differences of weight percentages of the three cumulative size fractions (">5 mm", "from 5 to $2 \mathrm{~mm}$ "; " $<2 \mathrm{~mm}$ "); (2) to draw distribution diagrams describing the pattern of the material thrown at different distances from the line of travel of the spreader (Virin et al. 2008; Van Liedekerke et al. 2008). These diagrams were calculated both taking into account the coefficient of variation (CV) versus the working width, as requested by EN 13080 (CEN 2002), and expressing the weighed amount of distributed material as collection rate (CR) expressed as percentage of the highest amount collected by one single container belonging to the same repetition: in this way, as long as the tractor advances, formulations with higher CRs tend to flow from the spreader's hopper more slowly than those showing lower CRs.

All data underwent statistical analysis with " $R$ " statistical software (R Development Core Team 2008) by means of analysis of variance (ANOVA) followed by Fisher least significant difference (LSD) test for physical features means 
Fig. 3 View of the experimental facility during one spreading trial

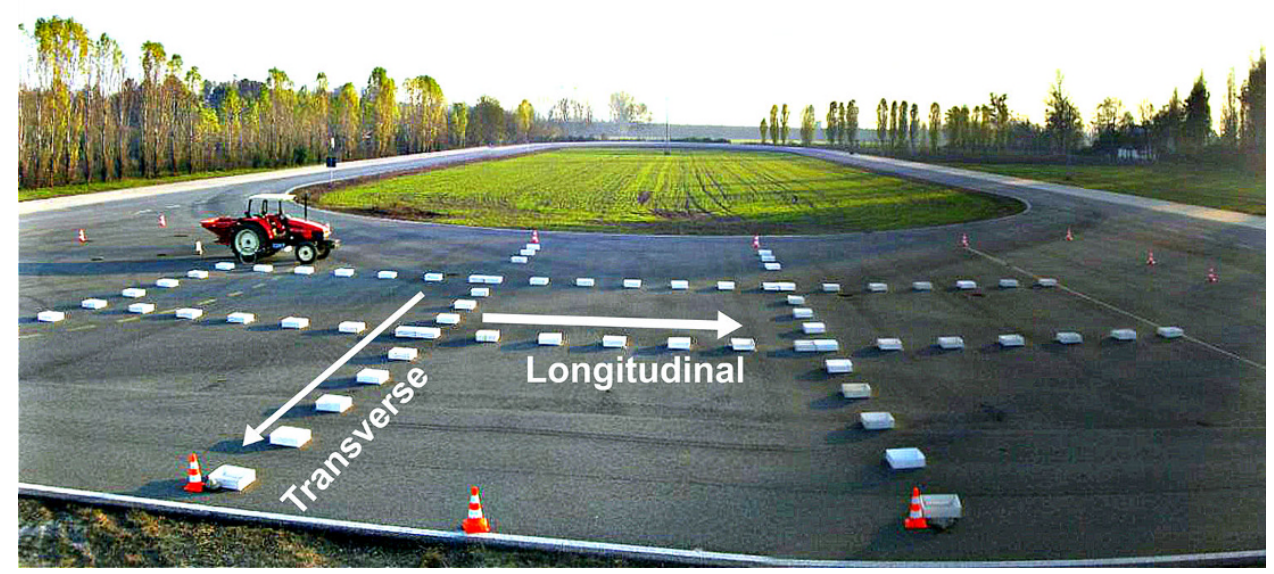

Fig. 4 Schematic showing the arrangement of the collection containers according to longitudinal (from 1 to 7 ) and transverse (from 1 to 9 ) replications

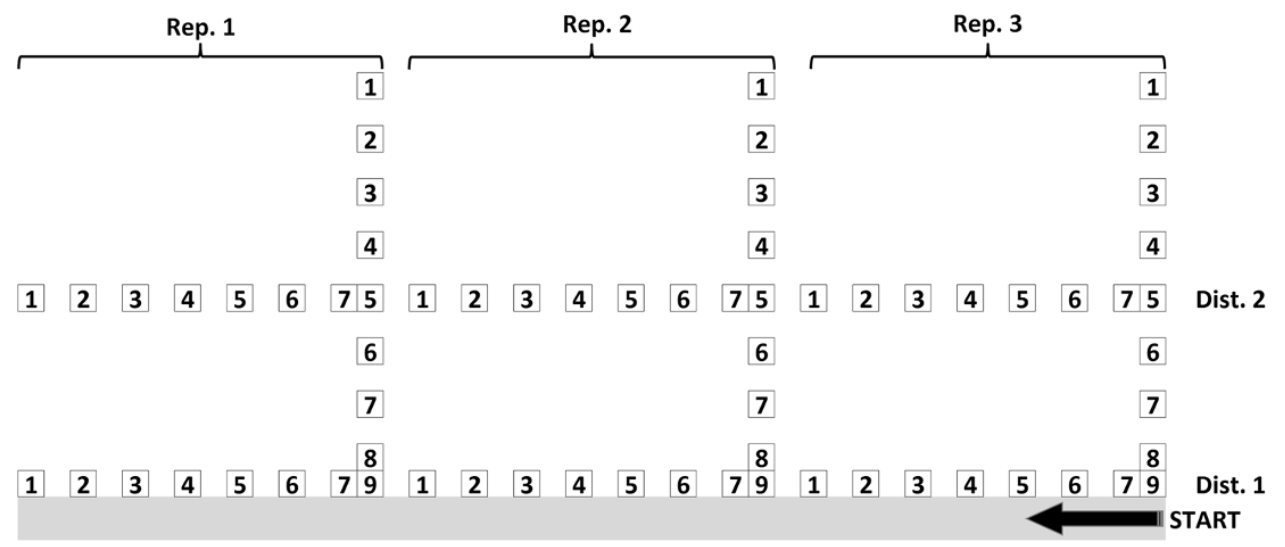

and Duncan multicomparison test with $5 \%$ probability LSD for CRs. Distribution maps were drawn by means of "Surfer 8.0" software (Goldensoftware Inc., USA).

\section{Results and discussion}

Pellet chemical and physical properties

Comparisons among the tested products did not point out any significant difference between SMSF, SMSF-SD and the reference material as far as $\mathrm{OM}, \mathrm{TKN}$ and $\mathrm{C} / \mathrm{N}$ ratio are concerned. In particular: (1) OM ranged $51.3 \pm 2.0 \%$ for SMSF $67.6 \pm 4.3 \%$ for mixed manure and chicken manure; (2) TKN ranged $2.8 \%$ of mixed manure $-4.5 \%$ of chicken manure with SMSF and SMSF-SD both around $2.9 \pm 0.2 \%$; (3) $\mathrm{C} / \mathrm{N}$ ratio ranged 10.2 $\pm 0.9-13.6 \pm 0.2$ of mixed manure, in good agreement with the values presented by Wang et al. (2004) for different manure/biomass mixtures and reviewed by Bernal et al. (2009).

SMSF-WC and SMSF-WS samples differenced from the previous ones because of their significant lower OM content ranging 19.7-20.9\%: this can be ascribed to the effect of such bulking agents on windrow porosity, which can lead to high organic matter degradation (Larney et al. 2008; Petric et al. 2009).

Table 1 shows the results of the physical properties of the material at spreading: moisture content was quite different among the various samples ranging $4.2 \%$ (SMSFWS) $-12.5 \%$ (SMSF and mixed manure). These values agree with the results of Alemi et al. (2010), according to whom the best level of water content for pellet hardness and durability is $11 \%$ when ground manure is the raw material, and with the value of $9.5 \%$ reported by Gavalda et al. (2010) who worked with heat-dried pellets made from wastewater plant sludge. In case of granular organo-mineral fertilizers, Paré et al. (2010) found water content ranging 9.0-23.0\% depending on the used raw material and of the adopted physical separation procedure.

Bulk density ranged $543.8 \pm 27.3 \mathrm{~kg} \mathrm{~m}^{-3}$ for chicken manure-701.1 $\pm 13.4 \mathrm{~kg} \mathrm{~m}^{-3}$ for SMSF-SD. According to ANOVA and Fisher LSD test, sample composition significantly affects moisture content highlighting different classes among the tested materials. "Mixed manure" is the reference organic fertilizer with the closest bulk density to that of the tested organic formulations. 
Table 1 Main chemical and physical properties of the tested pellets

\begin{tabular}{lllll}
\hline Pellet composition & Moisture (\%) & Pellet length (mm) & Pellet diameter (mm) & Bulk density (kg m $^{-3}$ ) \\
\hline SMSF & $12.5 \pm 0.38(\mathrm{~d})$ & $13.1 \pm 3.35(\mathrm{a}-\mathrm{c})$ & $5.51 \pm 0.52(\mathrm{c})$ & $669.8 \pm 15.7(\mathrm{~d}, \mathrm{e})$ \\
SMSF-SD & $9.06 \pm 0.31(\mathrm{~b})$ & $13.9 \pm 3.29(\mathrm{a}-\mathrm{c})$ & $5.48 \pm 0.48(\mathrm{~b}, \mathrm{c})$ & $701.1 \pm 13.4(\mathrm{e})$ \\
SMSF-WC & $5.14 \pm 0.57$ (a) & $14.6 \pm 4.17(\mathrm{a}-\mathrm{c})$ & $5.35 \pm 0.46(\mathrm{a}, \mathrm{b})$ & $312.2 \pm 51.4(\mathrm{a})$ \\
SMSF-WS & $4.18 \pm 0.11(\mathrm{a})$ & $30.2 \pm 9.57(\mathrm{e})$ & $5.91 \pm 0.22(\mathrm{~d})$ & $632.7 \pm 24.1(\mathrm{~d}, \mathrm{c})$ \\
Mixed manure & $12.5 \pm 0.12(\mathrm{~d})$ & $11.8 \pm 3.03(\mathrm{a}, \mathrm{b})$ & $4.05 \pm 0.27(\mathrm{a})$ & $595.8 \pm 2.69(\mathrm{c})$ \\
Chicken manure & $10.5 \pm 0.75(\mathrm{c})$ & $15.0 \pm 4.88(\mathrm{~b}-\mathrm{d})$ & $3.94 \pm 0.15(\mathrm{a})$ & $543.8 \pm 27.3(\mathrm{~b})$ \\
\hline
\end{tabular}

Data are expressed as mean \pm SD of three replicates. Lowercase letters indicate significant differences between averages at $P<0.05$ level (Fisher LSD test)

These values are slightly higher than those of Rao et al. (2007), which ranged $325-480 \mathrm{~kg} / \mathrm{m}^{3}$ (average $390 \mathrm{~kg} / \mathrm{m}^{3}$ ) for pig slurry solid compost batches. Nevertheless, they fully agree with the range reported by Lawong et al. (2011), who produced pelleted organic fertilizer from cow and poultry dung and are also comparable with those published by Paré et al. (2010) and Allaire and Parent (2004) for organo-mineral fertilizers with granular formulation.

As far as pellet dimensions are concerned, the diameter of formulation always significantly differed from the reference products and this is attributable to the pelletizer that was used. At the same time, such distinction was not detectable with reference to pellet length where the reference material was always comparable to the length of the pellets of the produced formulations. Indicating a sort of standardizing effect caused by the pelletization process. This was confirmed by SGN $(600 \mathrm{~mm})$ and UI (from 99 to $100 \%$ ) values: SGN in particular complied with the recommendations of Polyankov et al. (1985), cited by Paré et al. $(2009,2010)$ who suggested SGN should range $400-700 \mathrm{~mm}$ to prevent nutrient losses from organo-mineral fertilizer granules.
Pellet fragmentation following distribution

Figure 5 shows that spreading operation resulted in breaking larger pellets into smaller particles: more in detail, all the tested formulations behaved differently from the provided reference material as consequence of pellet's diameter. In particular SMSF-WC is the one that is affected the least with $-1.7 \pm 1.0 \%$ in the fraction "above $5 \mathrm{~mm}$ " while SMSF, SMSF-SD and SMSF-WS (ranging $-6.5 \pm 2.2$ to $-7.2 \pm 0.4 \%$ ) do not significantly differ from each other. The same pattern of differences was found also in the increased amounts of the " $5-2 \mathrm{~mm}$ " fraction where the two reference products significantly differ from each other and with the other samples. Again, SMSF-WC is the pelleted formulation that differs the most from the others because the increase in weight of this fraction completely compensates the loss observed in the previous size class. All the tested materials (with exception for SMSF-WC) show substantial increase in the " $<2 \mathrm{~mm}$ " size fraction and these increments are comparable with those of "mixed manure" and "chicken manure". Data processing showed that moisture content (Table 1) significantly affected this behavior in accordance with Alemi et al. (2010) who reported decreasing levels of
Fig. 5 Changes in pellet size distribution resulting from the spreading operation

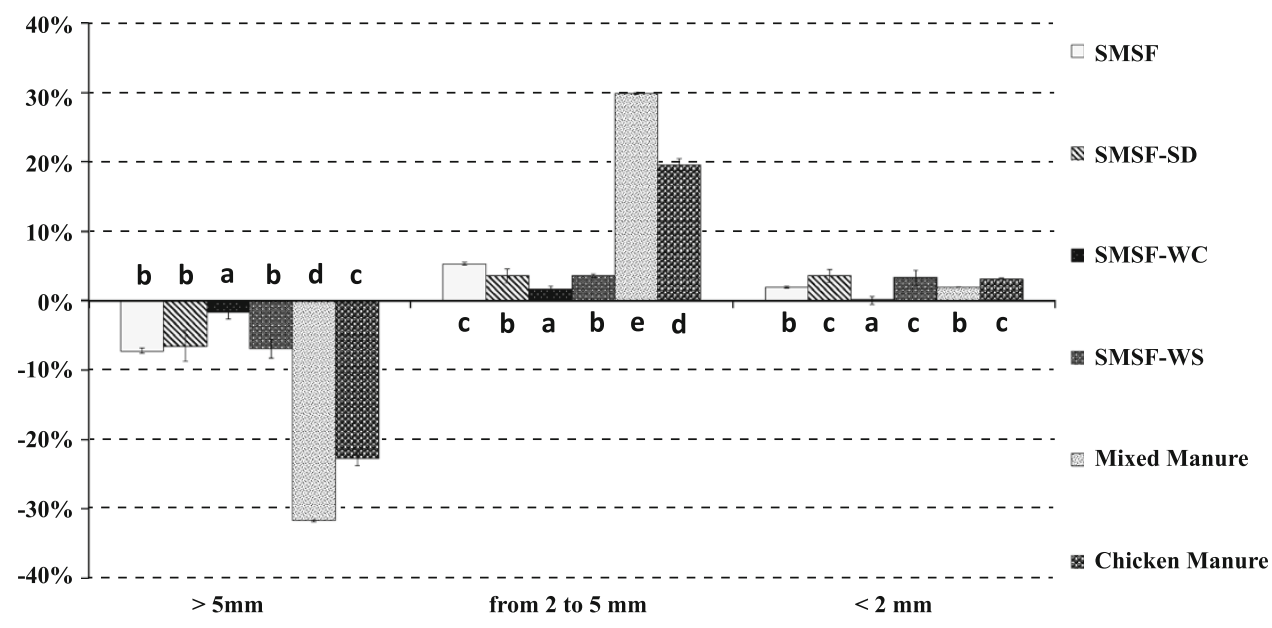

Lowercase letters indicate significant differences between averages at $\mathrm{P}<0.05$ level according to Fisher LSD test 
Table 2 ANOVA on material amounts collected along the longitudinal direction

a Significance at Duncan LSD test $=*$ significant at $P<0.01$, **significant at $P<0.05$ n.s. Not significant

Table 3 Duncan multiple comparisons on average CRs collected in longitudinal way

Data are grouped according to variable factors: lowercase letters indicate significant differences between samples along the same column; uppercase letters highlight significant differences between different columns

\begin{tabular}{|c|c|c|c|c|c|}
\hline Variation source & $d f$ & Square sum & $\begin{array}{l}\text { Mean } \\
\text { square }\end{array}$ & $F$ & Sig. ${ }^{\text {a }}$ \\
\hline Pellet formulation & 5 & $45,727.08$ & $9,145.41$ & 22.7407 & $* *$ \\
\hline Container longitudinal position & 6 & $6,697.43$ & $1,116.24$ & 2.7756 & $*$ \\
\hline Distance & 1 & $73,565.62$ & $73,565.62$ & 182.9258 & $* *$ \\
\hline Pellet formulation $\times$ longitudinal distance & 30 & $9,386.30$ & 312.88 & 0.7780 & n.s. \\
\hline Pellet formulation $\times$ transverse distance & 5 & $15,703.365$ & $3,140.67$ & 7.8095 & $* *$ \\
\hline Container longitudinal position $\times$ transverse distance & 6 & $1,356.76$ & 226.13 & 0.5623 & n.s. \\
\hline $\begin{array}{l}\text { Pellet formulation } \times \text { longitudinal } \\
\text { position } \times \text { transverse distance }\end{array}$ & 30 & $6,257.035$ & 208.57 & 0.5186 & $*$ \\
\hline Treatments & 83 & $158,693.58$ & $1,911.97$ & 4.7542 & $* *$ \\
\hline Error & 168 & $67,563.028$ & 402.16 & & \\
\hline Total & 251 & $226,256.61$ & & & \\
\hline
\end{tabular}

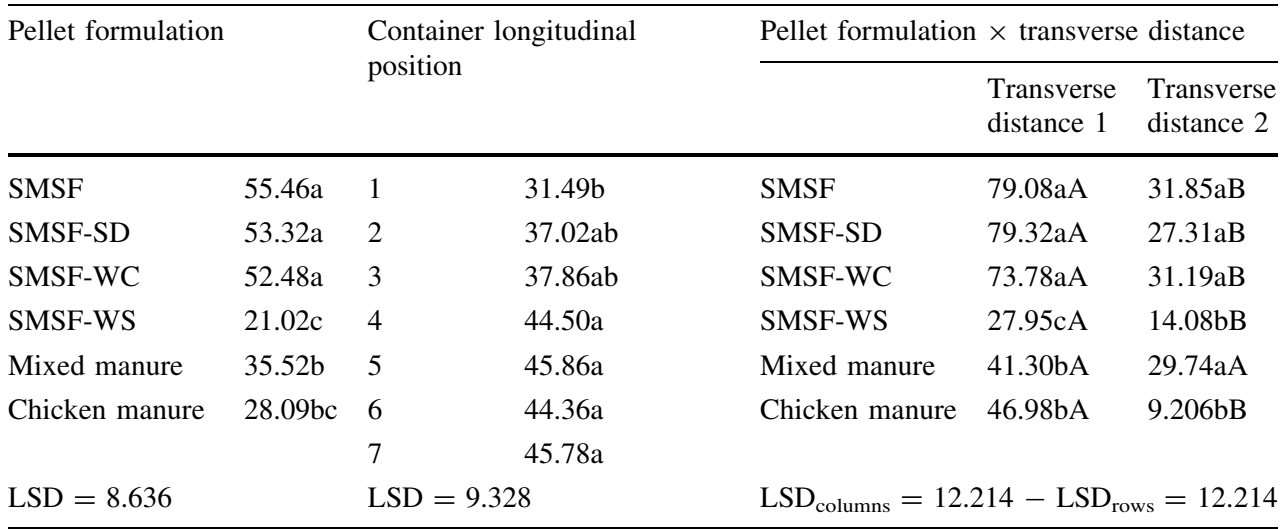

pellet solidity at increasing levels of moisture. Moreover, the addition of wood chips can be the key point of this as lignin, which is not completely degraded during the composting phase (Tuomela et al. 2000), acts as a binder, positively affecting pellet strength (Kaliyan and Morey 2009).

\section{Pellet distribution patterns}

With reference to the distributed amounts of pellet, statistical analysis on longitudinal pellet CRs showed that pellet formulation greatly influenced $(P<0.001)$ the way organic fertilizers were spread along tractor direction of advancement (Table 2). Table 3 shows the results of the post hoc test (Duncan test) carried out on longitudinal distribution CRs: at varying of pellet formulation, SMSFWS turned out to be the one with the lowest CR followed by chicken manure while those with higher CRs were SMSF, SMSF-SD and SMSF-WC that did not show significant differences among them: given that these CRs are expressed as percentage of the highest amount collected by one single container belonging to the same repetition, SMSF, SMSF-SD and SMSF-WC where the formulations emptying the hopper of the spreader less rapidly than SMSF-WS, chicken manure and Mixed manure did.

As far as container longitudinal position is concerned (Table 3, central column) it was pointed out that along the first $3.5 \mathrm{~m}$ of each repetition, regardless the formulation, pellet CR averagely ranged 44.6-45.9\% with no significant differences between these containers; things significantly changed at the end of the repetition where container $n .1 \mathrm{CR}$ was $30 \%$. The role of pellet formulations turned out to be significant even when distance factor was considered (Table 3, right column): containers placed farther away from the spreader intercepted on average $56.8 \%$ less than those in the close position; along the same row SMSF-WS formulation was the one less intercepted in both the considered distances while SMSF, SMSF-SD and SMSF-WC were the pellet formulations showing significantly higher CRs.

The same analysis carried out on transverse distribution CRs is shown in Table 4: here, pellet formulation turned out not to be significant as container longitudinal position did: in particular it turned out that up to $4 \mathrm{~m}$ far from spreader pellet CRs showed non-significant differences (Table 4, right column), no matter pellet formulation. Given this, the attention 
Table 4 ANOVA on material collected along the transverse direction

${ }^{\text {a }}$ Significance $=* *$ significant at $P<0.05$

n.s. Not significant

Fig. $6 \mathrm{CV}$ of the tested pellets (\%) plotted versus the working width (m)

Fig. 7 Longitudinal and transverse distribution patterns of SMSF-SD, SMSF, "mixed manure" and "chicken manure"

\begin{tabular}{lrrrrl}
\hline Variation source & $d f$ & Square sum & Mean square & \multicolumn{1}{c}{$F$} & Sig. $^{\text {a }}$ \\
\hline Pellet formulation & 5 & $3,281.14$ & 656.23 & 1.8398 & n.s. \\
Container longitudinal position & 8 & $82,939.16$ & $10,367.40$ & 29.0656 & $* *$ \\
Pellet formulation $\times$ longitudinal position & 40 & $16,399.41$ & 409.98 & 1.1494 & n.s. \\
Treatments & 53 & $102,619.72$ & $1,936.22$ & 5.4283 & $* *$ \\
Error & 108 & $38,522.50$ & 356.69 & & \\
Total & 161 & $141,142.22$ & & & \\
\hline
\end{tabular}

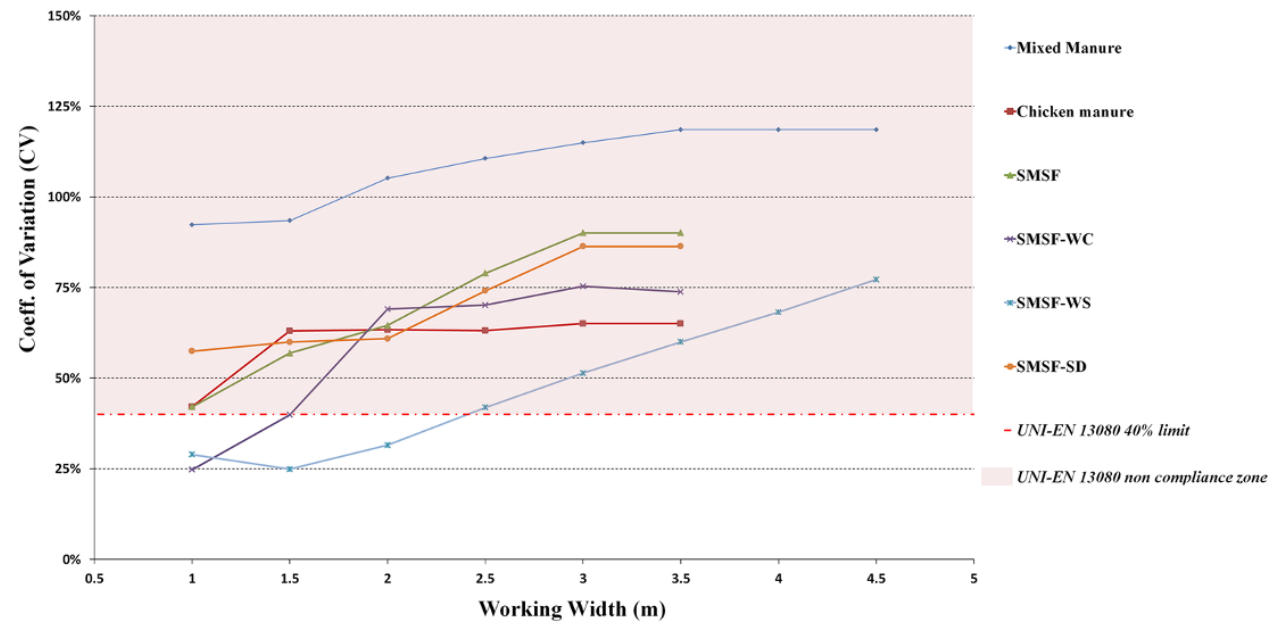

Mixed Manure

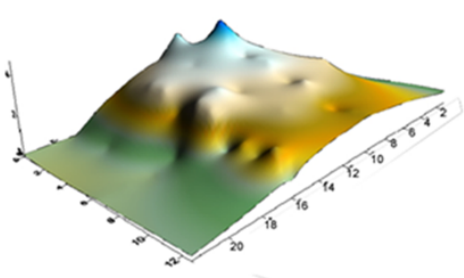

Longitudinal value $46.14 \pm 18.70$ (a)

Transverse value: $1.53 \pm 1.34$ (bc)

SMSF-SD

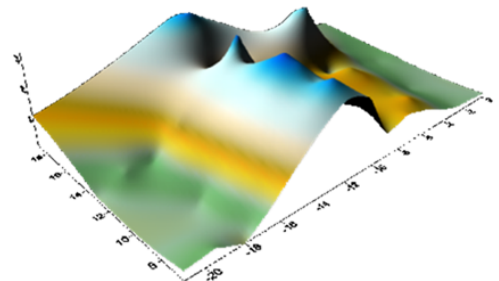

Longitudinal value $58.05 \pm 26.59$ (a) Transverse value: $5.58 \pm 3.81$ (a)
Chicken manure

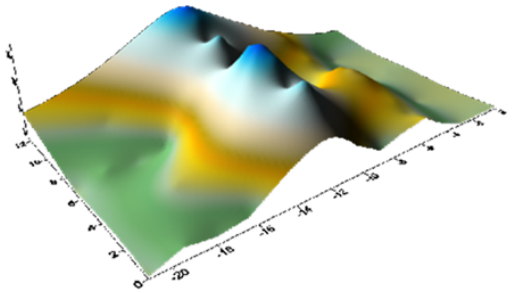

Longitudinal value $55.46 \pm 27.38$ (a) Transverse value: $3.00 \pm 2.92$ (b)

SMSF

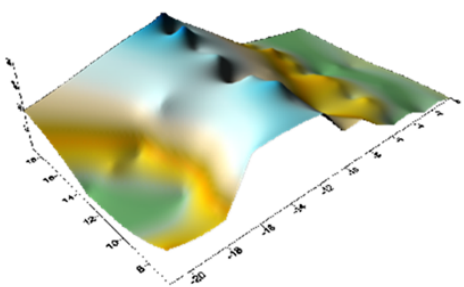

Longitudinal value $29.05 \pm 34.81$ (b)

Transverse value: $6.37 \pm 4.71$ (a) 
Table 5 Duncan multiple comparisons on average CRs collected along the transverse direction

\begin{tabular}{llll}
\hline Pellet formulation & & \multicolumn{2}{l}{ Container transversal position } \\
\hline SMSF & $33.71 \mathrm{a}$ & 1 & $2.976 \mathrm{c}$ \\
SMSF-SD & $32.36 \mathrm{a}$ & 2 & $5.490 \mathrm{c}$ \\
SMSF-WC & $24.54 \mathrm{a}$ & 3 & $10.74 \mathrm{c}$ \\
SMSF-WS & $24.80 \mathrm{a}$ & 4 & $16.60 \mathrm{bc}$ \\
Mixed manure & $33.33 \mathrm{a}$ & 5 & $35.62 \mathrm{ab}$ \\
Chicken manure & $36.18 \mathrm{a}$ & 6 & $40.41 \mathrm{a}$ \\
& & 7 & $37.96 \mathrm{a}$ \\
& & 8 & $52.73 \mathrm{a}$ \\
& & 9 & $74.86 \mathrm{a}$ \\
LSD $=14.92633$ & & LSD $=19.93790$
\end{tabular}

Lowercase letters indicate significant differences between samples (interaction between pellet Pellet formulation and container position is not shown because not significant, see Table 4)

was driven at first to the variation of the $\mathrm{CV}$ throughout the working width in compliance with CEN (2002), and subsequently to the amount of pellet intercepted by each container. EN 13080 standard (CEN 2002) assess that the CV of the spread amounts shall be $<40 \%$ : among the tested materials the only formulations complying with such limit were SMSFWS and SMSF-WC: the former had CV lower than $40 \%$ up to $2.0 \mathrm{~m}$ from the spreading equipment (ranging 24.7-31.5\%), the latter complies up to $1.5 \mathrm{~m}$ of distance ranging 24.7-39.9\% (Fig. 6). This was confirmed by distribution diagrams representing the intercepted amount of pellet (g) at varying of containers' spatial coordinates (Fig. 7): here, SMSF and SMSF-SD were the formulations showing average transverse collection amounts significantly higher than those of the references while, as far as longitudinal distribution is concerned, SMSF-SD only was the formulation whose collected amount was comparable to those of mixed manure and chicken manure (Table 5).

The particular behavior shown by SMSF-WS, SMSFWC and SMSF-SD can be attributed to the peculiar pellet resistance to fragmentation induced by rotor vanes action (Fig. 5). Formulations fragmenting the least are those ending up with better transverse and longitudinal distribution. An explanation of this can be found in the work of Suppadit et al. (2012) who, working on quail litter pellets, highlighted the fact that higher moisture content is negatively related to many physical properties including rupture force of pellets (and, as displayed in Table 1, these three formulations are those with the lower moisture content).

\section{Conclusions}

On farm pelletization of SMSF composted with different organic waste materials as co-formulates can turn into organic fertilizer formulations comparable with pelleted organic fertilizers ordinarily available at retailers. SMSFWC was the formulation with the best resistance to fragmentation induced by spreader vanes. SMSF-SD was the formulation showing better longitudinal and transverse distribution while SMSF was the one showing good transverse but poor longitudinal distribution. These promising results enhance the importance of co-composting as a way to increase livestock farming sustainability and produce better manure compost for wider agricultural uses. Further studies are still required to assess the compliance of these products with law requirements.

Acknowledgments This work was carried out within the framework of the "FITRAREF" project, funded by the Italian Ministry of Agriculture and Forestry (OIGA call, 2009), under the scientific direction of Dr. Eugenio Cavallo (CNR-IMAMOTER). Authors also acknowledge Mr. Elia Premoli (CRA-ING, Laboratory of Treviglio) for his valuable help and participation in setting up the experimental facility, the spreading machine as well as in carrying out the spreading trials.

Conflict of interest The authors declare that they have no competing interests.

Authors' contributions All authors have made adequate effort on all parts of the work necessary for the development of the manuscript according to their expertise.

Open Access This article is distributed under the terms of the Creative Commons Attribution License which permits any use, distribution, and reproduction in any medium, provided the original author(s) and the source are credited.

\section{References}

Agnew JM, Leonard JJ (2003) Physical properties of compost: literature review. Compost Sci Util 11:238-264

Alemi H, Kianmehr MH, Borghae E (2010) Effect of pellet processing of fertilizer slow-release nitrogen in soil. Asian $\mathrm{J}$ Plant Sci 9(2):74-80

Allaire SE, Parent LE (2003) Size guide number and Rosin-Rammler approaches to describe particle size distribution of granular organic-based fertilisers. Biosyst Eng 86(4):503-509

Allaire SE, Parent LE (2004) Physical properties of granular organicbased fertilisers, part 1: static properties. Biosyst Eng 87(1):79-87

Aphale A, Bolander N, Park J, Shaw L, Svec J, Wassgren C (2003) Granular fertiliser particle dynamics on and off a spinner spreader. Biosyst Eng 85(3):319-329

ASTM D3174-11 Standard test method for ash in the analysis sample of coal and coke from coal. doi:10.1520/D3174-11

Ball BC, Mc Taggart IP, Scott A (2004) Mitigation of greenhouse gas emissions from soil under silage production by use of organic manures or slow-release fertilizer. Soil Use Manag 20:287-295

Battacharya SC, Sett S, Shrestha RM (1989) State of the art for biomass densification. Energy Sources 11(3):161-182

Bernal MP, Paredes C, Sanchez-Monedero MA, Cegarra J (1998) Maturity and stability parameters of composts prepared with a wide range of organic wastes. Bioresour Technol 63:91-99

Bernal MP, Alburquerque JA, Moral R (2009) Composting of animal manures and chemical criteria for compost maturity assessment. A review. Bioresour Technol 100(22):5444-5453 
Bishop PL, Godfrey C (1983) Nitrogen transformation during sewage composting. BioCycle 24:34-39

Brito LM, Mourão I, Coutinho J, Smith SR (2012) Simple technologies for on-farm composting of cattle slurry solid fraction. Waste Manag 32(7):1332-1340

Bustamante MA, Alburquerque JA, Restrepo AP, De la Fuente C, Paredes C, Moral R, Bernal MP (2012) Co-composting of the solid fraction of anaerobic digestates, to obtain added-value materials for use in agriculture. Biomass Bioenerg 43:26-35

Caceres F, Flotats X, Marfa O (2006) Changes in the chemical and physiochemical properties of the solid fraction of cattle slurry during composting using different aeration strategies. Waste Manag 26:1081-1091

Campbell CM, Fulton JP, Wood CW (2010) Utilizing nutrient overmass distribution patterns for assessment of poultry litter spreaders. Trans ASABE 53(3):659-666

CEN-European Committee for Standardization (2002) European Standard EN 13080: agricultural machinery, manure spreaders, environmental protection, requirements and test methods

Development Core Team R (2008) R: a language and environment for statistical computing. R Foundation for Statistical Computing, Vienna. ISBN 3-900051-07-0

Dries L, Ciaian P, Kancs D (2012) Job creation and job destruction in EU agriculture. Food Policy 37:600-608

EU (1991) Council Directive of 12th December 1991, number 91/676/EEC. Off J Eur Communities L375

EU (2000) Council Directive of 23rd October 2002, number 2000/60/ EC. Establishing a framework for community action in the field of water policy. Off J Eur Communities L327

EU (2003) Regulation (EC) No. 2003/2003 of the European Parliament and of the Council of 13 October 2003 relating to fertilisers. Off J Eur Union L 304:0001-0194

FAO-Food and Agriculture Organization of the United Nations (2012). http://www.faostat.fao.org. Accessed March 2012

Gadernejad K, Zafari A, Kianmehr MH (2012) Effects of pressure, mold diameter and raw material properties on energy consumption in producing dairy cattle manure pellets. Agric Eng Int CIGR J 14:86-92

Gavalda D, Scheiner JD, Revel JC, Merlina G, Kaemmerer M, Pinelli E, Guiresse M (2010) Agronomic and environmental impacts of single application of heat-dried sludge on an Alfisol. Sci Total Environ 343:97-109

Georgakakis D, Tsavdaris A, Bakouli J, Symeonidis S (1996) Composting solid swine manure and lignite mixtures with selected plant residues. Bioresour Technol 56:195-200

Grift TE, Kweon G, Hofstee JW, Piron E, Villette S (2006) Dynamic friction coefficient measurement of granular fertiliser particles. Biosyst Eng 95(4):507-515

Hayakawa A, Akiyama H, Sudo S, Yagi K (2009) $\mathrm{N}_{2} \mathrm{O}$ and NO emissions from an Andisol field as influenced by pelleted poultry manure. Soil Biol Biochem 41:521-529

Hjorth M, Christensen KV, Christensen ML, Sommer SG (2010) Solid-liquid separation of animal slurry in theory and practice. A review. Agron Sustain Dev 30:153-180

Hofstee JW (1994) Handling and spreading of fertilizers: part 3, measurement of particle velocities and directions with ultrasonic transducers, theory, measurement system and experimental arrangements. J Agric Eng Res 54:1-16

Hofstee JW (1995) Handling and spreading of fertilizers: part 5, the spinning disc type fertilizer spreader. J Agric Eng Res 62:143-162

Hofstee JW, Huisman W (1990) Handling and spreading of fertilizers: part 1: physical properties of fertilizer in relation to particle motion. J Agric Eng Res 47:213-234

Huang GF, Wu QT, Wong JWC, Nagar BB (2006) Transformation of organic matter during co-composting of pig manure with sawdust. Bioresour Technol 97(15):1834-1842
ISTAT-Italian National Statistical Institute (2012) Preliminary results of the 6th general census of agriculture. http://censimen toagricoltura.istat.it. Accessed Sept 2012

Jørgensen K, Jensen LS (2009) Chemical and biochemical variation in animal manure solids separated using different commercial separation technologies. Bioresour Technol 100(12):30883096

Kaliyan N, Morey RV (2009) Factors affecting strength and durability of densified biomass products. Biomass Bioenerg 33(3):337-359

Kweon G, Grift TE (2006) Feed gate adaptation of a spinner spreader for uniformity control. Biosyst Eng 95(1):19-34

Larney FJ, Olson AF, Miller JJ, DeMaere PR, Zvomuya F, McAllister TA (2008) Physical and chemical changes during composting of wood chip-bedded and straw-bedded beef cattle feedlot manure. J Environ Qual 37(2):725-735

Lawong W, Hwangdee P, Thumma S, Lawong C (2011) Development of two pellet die organic fertilizer compression machine. Procedia Eng 8:266-269

Lesschen JP, Van Den Berg M, Westhoek HJ, Witzke HP, Oenema O (2011) Greenhouse gas emission profiles of European livestock sectors. Anim Feed Sci Tech 166-167:16-28

Li R, Wang JJ, Zhang Z, Shen F, Zhang G, Qin R, Li X, Xiao R (2012) Nutrient transformations during composting of pig manure with bentonite. Bioresour Technol 121:362-368

Lopez-Ridaura S, Van der Werf H, Paillat JM (2009) Environmental evaluation of transfer and treatment of excess pig slurry by life cycle assessment. J Environ Manag 90(2):1296-1304

Marquer P (2010) Pig farming in the EU, a changing section. Eurostat, Statistics in Focus 8/2010. European Commission, Agriculture and Fisheries

Martins C (2009) Farm structure survey in Italy-2007. Eurostat, Statistics in Focus 38/2009. European Commission, Agriculture and Fisheries

Mc Carthy G, Lawlor PG, Coffey L, Nolan T, Gutierrez M, Gardiner GE (2011) An assessment of pathogen removal during composting of the separated solid fraction of pig manure. Bioresour Technol 102:9059-9067

Mc Mullen J, Fasina O, Wood CW, Feng Y (2005) Storage and handling characteristics of pellets from poultry litter. Appl Eng Agric 21(4):645-651

Meade G, Lalor STJ, Mc Cabe T (2011) An evaluation of the combined usage of separated liquid pig manure and inorganic fertiliser in nutrient programmes for winter wheat production. Eur J Agron 34(2):62-70

Meijide A, Díez JA, Sánchez-Martín L, López-Fernández S, Vallejo A (2007) Nitrogen oxide emissions from an irrigated maize crop amended with treated pig slurries and composts in a Mediterranean climate. Agric Ecosyst Environ 121(4):383-394

MiPAAF-Ministero delle Politiche Agricole Alimentari e Forestali, Osservatorio Nazionale Pedologico e per la Qualità del Suolo Agricolo e Forestale (2012) Metodi di Analisi per i Fertilizzanti. Trinchera A, Leita L, Sequi P Eds. http://www.ciec-italia.it/ index_file/Documentazione_metodi_analisi_fertilizzanti.htm Accessed Sept 2012

Møller HB, Lund I, Sommer SG (2000) Solid-liquids separation of livestock slurry: efficiency and cost. Bioresour Technol 74(3):223-229

Møller HB, Sommer SG, Ahring BK (2002) Separation efficiency and particle size distribution in relation to manure type and storage conditions. Bioresour Technol 85(2):189-196

Moral R, Paredes C, Bustamante MA, Marhuenda-Egea F, Bernal MP (2009) Utilisation of manure composts by high-value crops: safety and environmental challenges. Bioresour Technol 100(22):5454-5460

Nielsen NPK, Gardner DJ, Poulsen T, Felby C (2009) Importance of temperature, moisture content, and species for the conversion 
process of wood residues into fuel pellets. Wood Fiber Sci 41:414-425

Nolan T, Troy SM, Healy MG, Kwapinsky W, Leahy JJ, Lawlor PG (2011) Characterization of compost produced from separated pig manure and a variety of bulking agents at low initial $\mathrm{C} / \mathrm{N}$ ratios. Bioresour Technol 102(14):7131-7138

Paré CM, Allaire SM, Khiari L, Nduwamungu C (2009) Physical properties of organo-mineral fertilizers-short communication. Can Biosyst Eng 51:3.21-3.27

Paré CM, Allaire SM, Parent LE, Khiari L (2010) Variation in the physical properties of organo-mineral fertilisers with proportion of solid pig slurry compost. Biosyst Eng 106:243-249

Parish RL (2006) Review of granular applicators for turfgrass. Hort Technol 16(3):533-538

Petersen SO, Sommer SG, Béline F, Burton C, Dach J, Dourmad YJ, Leip A, Misselbrook T, Nicholson F, Poulsen HD, Provolo G, Sørensen P, Vinnerås B, Weiske A, Bernal MP, Böhm R, Juhász C, Mihelic R (2007) Recycling of livestock manure in a wholefarm perspective. Livest Sci 112(3):180-191

Petric I, Šestan A, Šestan I (2009) Influence of wheat straw addition on composting of poultry manure. Process Saf Environ 87(3):206-212

Polyankov VT, Bobkov VN, Nikilina MS (1985) The influence of the granule size of peat mineral fertilizers on potato yields. Torfianaya Promyshlenost 11:16-17 (in Russian)

Rao JR, Watabe M, Stewart TA, Cherie Millar B, Moore JE (2007) Pelleted organo-mineral fertilizers from composted pig slurry solids, animal wastes and spent mushroom compost for amenity grasslands. Waste Manag 27(9):1117-1128

Rees RM, Baddeley JA, Bhogal A, Ball BC, Chadwick DR, Macleod M, Lilly A, Pappa VA, Thorman RE, Watson AC, Williams JR (2013) Nitrous oxide mitigation in UK agriculture. Soil Sci Plant Nutr 59(1):3-15

Roca-Pérez L, Martínez C, Marcilla P, Boluda R (2007) Composting rice straw with sewage sludge and compost effects on the soilplant system. Chemosphere 75(6):781-787

Suppadit T, Panomsri S (2010) Broiler litter pelleting using Siriwan model machine. J Agric Technol 6:439-448

Suppadit T, Ponpiachan S, Panomsri S (2012) Effect of moisture content in quail litter on the physical characteristics of the pelleting using a Siriwan model machine. Anim Sci J 83(4):350-357

Tabil LG, Sokhansanj S (1996) Process conditions affecting the physical quality of alfalfa pellets. Appl Eng Agric 12:345-350

Tomich TP, Brodt S, Ferris H, Galt R, Horwath WR, Kebreab E, Leveau JHJ, Liptzin D, Lubell M, Merel P, Michelmore R, Rosenstock T, Scow K, Six J, Williams N, Yang L (2011) Agroecology: a review from a global-change perspective. Annu Rev Environ Resour 36:193-222

Tumuluru JS, Wright CT, Hess JR, Kenney KL (2011) A review of biomass densification systems to develop uniform feedstock commodities for bioenergy application. Biofuels Bioprod Bioref 5:683-707

Tuomela M, Vikman M, Hatakka A, Itävaara M (2000) Biodegradation of lignin in a compost environment: a review. Bioresour Technol 72(2):169-183

Van Liedekerke P, Piron E, Van Geyte J, Villette S, Ramon H, Tijskens E (2008) Recent results of experimentation and DEM modelling of centrifugal fertilizer spreading. Granul Matter 10(4):247-255

Vereijken PH, Hermans CML (2010) A quick scan tool to assess the relative prospects of European regions for sustainable agriculture in a liberal market. Land Use Policy 27:440-448

Virin T, Koko J, Piron E, Martinet P, Berducat M (2008) Optimization-based approach for better centrifugal spreading. Int J Syst Sci 39(9):913-924

Wang P, Changa CM, Watson ME, Dick WA, Chen Y, Hoitink HAJ (2004) Maturity indices for composted dairy and pig manures. Soil Biol Biochem 36:767-776

Zafari A, Kianmehr MH (2013) Application of densification process in organic waste management. Waste Manag Res 31(7):684-691

Zebarth BJ, Chabot R, Coulombe J, Simard RR, Douheret J, Tremblay N (2005) Pelletized organo-mineral fertilizer product as a nitrogen source for potato production. Can J Soil Sci 85(3):387-395

Zhang RH, Westerman PW (1997) Solid-liquid separation of animal manure for odor control and nutrient management. Appl Eng Agric 13(5):657-664 